\title{
Location preferences of fission products in high density $U(M o)$ dispersion fuel element
}

\begin{abstract}
In the frame of the RERTR (Reduced Enrichment for Research and Test Reactors) program a fuel element is being developed with the concept of high density bcc uranium that can remain stable during fabrication and later irradiation, dispersed in aluminum powder. The whole constitutes a compact material which is later rolled with an aluminum-silicon clad plate. Under further irradiation, an interaction layer (IL) grows through a diffusion process around the fuel element particle, leading to the swelling of the fuel element and formation of pores. This behavior can lead to catastrophic failure of the disperse fuel. Therefore it is our great interest to gain knowledge about the influence the fission products (FP) have over the IL formation and swelling. The stable compounds that have been observed in the IL of $\mathrm{U}(\mathrm{Mo}) / \mathrm{Al}(\mathrm{Si})$ tested in diffusion pair experiments are $\mathrm{U}(\mathrm{Al}, \mathrm{Si})_{3}, \mathrm{USi}_{2}, \mathrm{U}_{1+\mathrm{x}} \mathrm{Si}_{2-\mathrm{x}}$, $\mathrm{U}_{3} \mathrm{Si}_{5} \mathrm{UMo}_{2} \mathrm{Al}_{20}$ and $\mathrm{U}_{6} \mathrm{Mo}_{4} \mathrm{Al}_{43}$. Among them, $\mathrm{U}(\mathrm{Al}, \mathrm{Si})_{3}$ has been observed to remain stable when subject to irradiation, delaying or stopping the IL swelling. Compositional analysis shows that $\mathrm{La}, \mathrm{Ce}$, Pr and Nd are some of the FP present in the burned dispersed fuel. Hence, these are the considered elements for a first evaluation of the problem that we performed in this work by means of computational methods.
\end{abstract}

Keywords: fission products, computational calculation, high density fuel, uranium, inter diffusion layer

\section{Introduction}

The development of fuels with low ${ }^{235} \mathrm{U}$ enrichment has become valuable over the course of the last twenty years, being of special interest fuels with high density of $\mathrm{U}(\mathrm{Mo})$ dispersion in $\mathrm{Al}$ matrices. The aim is to replace high enriched fuel by low enriched one with relative ${ }^{235} \mathrm{U} / \mathrm{U}_{\text {tot }}$ contents less than 0.2. Experimental evidence of $\mathrm{U}(\mathrm{Mo})$ under irradiation ${ }^{1-4}$ show the existence of an interaction layer (IL) between UMo and the Al matrix. The IL growth influences the mechanical integrity of the plates, generating a structural weakness. Swelling accumulation can ultimate lead to fuel plate failure. Characterization of the IL with different rates of fuel burn-up shows the presence of fission products (FP). ${ }^{5}$ In this way, $\mathrm{Sr}, \mathrm{Cs}, \mathrm{Nd}, \mathrm{La}$, $\mathrm{Ce}$ and $\mathrm{Xe}$ have been detected by electron probe microanalysis (EPMA), electron microscopy (SEM) and energy dispersive x-ray microanalysis (EDX). ${ }^{6}$ Other works have confirmed the nucleation and growth of fission gas bubbles (swelling) in the aluminum matrix. ${ }^{7,8}$ The FP accumulation has been observed by Huet et al., ${ }^{2}$ in the IL and aluminum matrix interface. FP implantation in Al matrices has been measured by EPMA, and Nd content has been estimated through Xe presence in the precipitation and formation of bubbles ${ }^{2}$ for the swelling effect. From another point of view, the irradiation of fuel plates of UMo show that the formation of the IL depends on the fission rate, and the swelling, on the other hand, depends on the burn-up or the fission density. ${ }^{9}$ Similar concepts have been reported regarding the FP-induced swelling, ${ }^{10}$ and the acceleration of swelling due to the influence of recrystallized phases of UMo. ${ }^{11}$ In agreement with experimental researches focusing on the influence of the FP in the IL, in the present work the configurational energy has been calculated, based on the functional density theory (DFT), of the disordered phases bcc U(Mo), bcc U(Mo, FP), fcc U(Mo)Al, fcc U(Mo,FP)Al, fcc $\mathrm{Al}$ and fcc $\mathrm{Al}(\mathrm{FP})$. The selected FP are Nd, Ce, La and Pr. The code used is VASP. ${ }^{12,13}$ In order to simulate disordered solutions the Special Quasi Random Structures (SQRS) ${ }^{14,15}$ was employed.

This work compares the results obtained through the calculus code to the experimental data in previously published papers. The goal of
Volume 3 Issue I - 2019

\author{
Paula R Alonso, 1,2 Mariano D Forti,,,2 Laura \\ Kniznik, ${ }^{1,2}$ Gerardo H Rubiolo, ${ }^{1,2,3}$ Darío N \\ Torres,' Pablo H Gargano,,2 \\ 'División Aleaciones Especiales, Argentina \\ ${ }^{2}$ Universidad Nacional de General San Martín, Argentina \\ ${ }^{3}$ CONICET,Argentina
}

\begin{abstract}
Correspondence: Paula R Alonso, Comisión Nacional de Energía Atómica, Avenida Gral. Paz 1499, C.P.: BI650KNA, General San Martín, Buenos Aires, Argentina, Tel +54 II 4839 6710,Email pralonso@cnea.gov.ar
\end{abstract}

Received: January 07, 2019 | Published: February 04, 2019 this article is to reinforce the experimental evidence regarding the effect of the accumulation of fission products and the influence during the swelling process on IL's behavior.

\section{Results and discussion}

In order to obtain a comparative chart of energies for the preference of rare earth atom to rest within the bcc $(\mathrm{U}, \mathrm{Mo})$ solid solution, or to be placed within the fcc $(\mathrm{U}, \mathrm{Mo}) \mathrm{Al}_{3}$ solid solution, we calculated the formation energies as:

$E_{f}=E_{T}(F P)-E_{T}(S S)-\sum_{i} n_{i} \mu_{i}$, where $E_{T}(F P)$ is the total energy calculated for the disordered structure with the substitution of one uranium atom by a FP atom, $E_{T}(S S)$ is the total energy for the bcc or fcc solid solution structure without substitution, $n_{i}$ is the quantity of substituted atoms (either -1 or +1 for the replaced uranium atom or the added FP atom) and $\mu_{i}$ are the chemical potential for the corresponding FP element. The key quantities in order to evaluate the host preference for the FP are the difference $\Delta^{1} \mathrm{E}_{\mathrm{f}}$ between defect formation energies of IL $\left(\mathrm{E}_{\mathrm{f}}{ }^{\text {int }}\right)$ and fuel $\left(\mathrm{E}_{\mathrm{f}}^{\text {fuel }}\right)$ and the difference $\Delta^{2} \mathrm{E}_{\mathrm{f}}$ between defect formation energies of IL and aluminum matrix $\left(\mathrm{E}_{\mathrm{f}}^{\text {matrix }}\right)$ : $\Delta^{1} E_{f}=E_{f}{ }^{\text {int }}-E_{f}{ }^{\text {fuel }} ; \Delta^{2} E_{f}=E_{f}{ }^{\text {int }}-E_{f}^{\text {matrix }}$. All corresponding values (Table 1) are negative, meaning that the situational defects have a preference for allocation within the interaction layer (IL) both in comparison with fuel and with the matrix. Our calculated result is in agreement with experimental evidence ${ }^{8}$ and predicts a consequent IL growth.

Table I Differences between formation energies of defect solid solutions $\Delta^{1} \mathrm{E}_{\mathrm{f}}$ and $\Delta^{2} \mathrm{E}_{\mathrm{f}}(\mathrm{eV})$

\begin{tabular}{lllll}
\hline$\Delta^{1} \mathrm{E}_{\mathrm{f}}$ & $-1,91$ & $-1,19$ & $-1,70$ & $-0,90$ \\
$\Delta^{1} \mathrm{E}_{\mathrm{f}}$ & $-1,67$ & $-0,73$ & $-0,62$ & $-0,79$ \\
\hline
\end{tabular}




\section{Conclusion}

Our results lead to the conclusion that the fission products taken into account would remain within the IL if the reaction takes place there, or they would move to the IL if it were possible. But we are prevented from a simplistic analysis by the knowledge that diffusion and migration play a fundamental role in the determination of the final location of the fission product in the different lattices. A careful diffusion analyses will be undertaken to enlighten the fission product behavior in a growing IL.

\section{Acknowledgments}

None.

\section{Conflict of interest}

Authors declare that there is no conflict of interest.

\section{References}

1. Huet F, Marelle V, Noirot J. International Meeting on Reduced Enrichment for Research and Test Reactors. Chicago, Illinois; 2003.

2. Huet F, Noirot J, Marelle V, et al. Post irradiation examinations on UMo full-sized plates - IRIS2 experiment. Transactions. 2005;36(22):92-97.

3. Van den Berghe S, Van Renterghem W, Leenaers A. Transmission electron microscopy investigation of irradiated $\mathrm{U}-7 \mathrm{wt} \%$ Mo dispersion fuel. Journal of Nuclear Science. 2008;375:340-346.

4. Baranov V, Nechaev V, Produvalov B. Atomic Energy. 2010;108(5):349357.

5. Dienst W, Nazare S, Thummler F. Irradiation behaviour of UAlx-Al dispersion fuels for thermal high flux reactors. Journal of Nuclear Materials. 1977;64:1-13.
6. Potter P, Ray I, Tamborini G. Managing Historic Hot Particle Liabilities in the Marine Envirioment. Nairm, Scotland; 2005.

7. Kaiser D, Jan Fong Jue, Miller B, et al. Scanning electron microscopy analysis of fuel/matrix interaction layers in highly-irradiated u-mo dispersion fuel plates with al and al-Si alloy matrices. Nuclear Engineering and Technology. 2014;46(2):147-158.

8. Leenaers A, Van den Berghe S, Koonen E, et al. Post-irradiation examination of uranium $-7 \mathrm{wt} \%$ molybdenum atomized dispersion fuel. Journal of Nuclear Materials. 2004;335:39-47.

9. Leenaers A, Van den Berghe S, Koonen E, et al. Fuel swelling and interaction layer formation in the SELENIUM Si and $\mathrm{ZrN}$ coated $\mathrm{U}(\mathrm{Mo})$ dispersion fuel plates irradiated at high power in BR2. Journal of Nuclear Materials. 2015;458:380-393.

10. Kim YS, Hofman GL. Fission product induced swelling of U-Mo alloy fuel. Journal of Nuclear Materials. 2011;419:291-301.

11. Leenaers A, Van Renterghem W, van den Berghe S. High burn-up structure of $\mathrm{U}(\mathrm{Mo})$ dispersion fuel. Journal of Nuclear Materials. 2016;476:218-230.

12. Hafner J. Ab $\square$ initio simulations of materials using VASP: Density $\square$ functional theory and beyond. Journal of Computational Chemistry. 2008;9(13):2044-2078.

13. Hafner J. Materials simulations using VASP - a quantum perspective to materials science. Computer Physics Commmunications. 2007;177(12):6-13.

14. Zunger A, Wei SH, Ferreira LG, et al. Special quasirandom structures. Phys Rev Lett. 1990;65:353.

15. Jiang C, Sordelet DJ, Gleeson B. Phys Rev B. 2005;72:184-203. 